Hsiao-Wei Wen • Wlodzimierz Borejsza-Wysocki • Thomas R. DeCory • Antje J. Baeumner • Richard A. Durst

\title{
A novel extraction method for peanut allergenic proteins in chocolate and their detection by a liposome-based lateral flow assay
}

Received: 1 February 2005 / Published online: 3 May 2005

(C) Springer-Verlag 2005

\begin{abstract}
In this study, conditions for extracting the major peanut allergen (Ara h1) from chocolate were optimized, and the extracted samples were analyzed by a lateral flow assay (LFA) using liposomal nanovesicles. The optimal conditions using peanut-spiked chocolate were found to be extraction with a mixture of phosphate buffered saline and hexane for $30 \mathrm{~min}$ at $35{ }^{\circ} \mathrm{C}$. After centrifugation, the buffer portion was treated with insoluble poly(vinylpolypyrrolidone) to remove phenolic compounds, and then analyzed by the LFA. The entire analysis, including sample preparation and LFA, could be easily completed within $2 \mathrm{~h}$, and the detection limit was $158 \mu \mathrm{g}$ of peanuts/g of chocolate.
\end{abstract}

Keywords Ara h1 . Chocolate - Lateral flow assay · Liposomal nanovesicles · Liposomes · Peanut allergen

\section{Introduction}

Peanut allergy affects between 0.6 and $1.0 \%$ of population in the westernized countries [1-3]. It accounts for most of food-induced anaphylactic reactions, and trace amounts of peanuts can induce mild allergic reactions [4-6]. Because no immunotherapy has been approved for peanut allergy, the only way to prevent allergic reactions is the strict avoidance of peanuts. However, accidental exposure to peanuts still happens frequently [7], so an efficient extraction method and a sensitive assay for detecting

H.-W. Wen · W. Borejsza-Wysocki · T. R. DeCory ·

R. A. Durst (

Department of Food Science and Technology,

Cornell University,

630 West North Street, Geneva, New York, 14456-0462

e-mail: rad2@cornell.edu

Tel.: 315-787-2297

Fax: 315-787-2397

\section{A. J. Baeumner}

Department of Biological \& Environmental Engineering, Cornell University,

Ithaca, NY, 14853 peanuts is urgently needed to protect peanut-allergic people.

As part of developing a sensitive assay, increasing the extraction efficiency of peanut allergens from food is an important requirement for detection of peanut contamination. Among the common peanut-contaminated foods, chocolate is especially difficult for detecting peanut allergens due to the excess of phenolic compounds and lipids. Phenolic compounds bind proteins with high affinity, resulting in a reduction of the interactions between allergens and antibodies [8]. To reduce this interference, gelatin or non-fat dry milk (NFDM) has been used as an additive in the extraction buffer [9-11]. In this study, insoluble poly(vinylpolypyrrolidone) replaced gelatin and NFDM due to its active and rapid absorbency of phenolic compounds [12]. Moreover, chocolate contains 30\% lipids [13], which can reduce the extraction efficiency by lowering protein solubility. The effects of delipidation on assay sensitivity for detecting peanut allergens in chocolate have not been published. Therefore, in this study, different organic solvents were used to investigate their effects on the extraction efficiency of Ara h1 from chocolate.

Ara h1 extracted from the peanut-spiked chocolate was detected in a previously developed LFA by using Ara h1tagged liposomal nanovesicles as the detector reagent [14]. A liposome is a spherical nanovesicle with an aqueous cavity surrounded by phospholipid bilayers. This cavity can carry a large number of marker molecules, allowing the result of the assay to be easily observed without additional processing [15]. The marker used in this study is the dye, sulforhodamine B (SRB). In this assay, Ara h1 in the sample competes with Ara h1-tagged liposomes for binding to the immobilized anti-Ara $\mathrm{h} 1$ antibodies on the test line in nitrocellulose membrane strips. The signal intensity of the test line is inversely proportional to the Ara h1 concentration in the sample. By using the optimized conditions to extract Ara h1 and then analyzing the extracted sample by the liposome-based assay, we can detect Ara h1 in a sample with a spiked concentration as low as $158 \mu \mathrm{g}$ of peanut/g of chocolate 


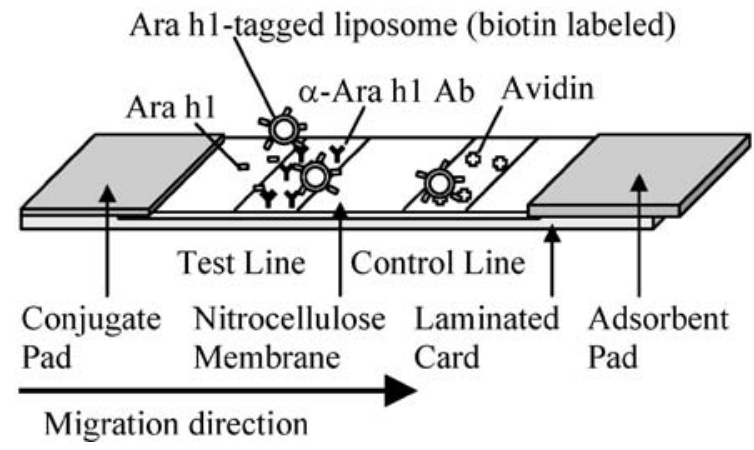

Fig. 1 Diagram of a test strip of the developed lateral flow assay. Anti-Ara h1 antibodies are coated on the test line in the nitrocellulose membrane as the capture reagent. Ara h1-tagged liposomes are the detector reagent, which compete with Ara h1 molecules extracted from peanut-spiked chocolate. On the control line, avidin captures the Ara h1-tagged liposomes through the biotin molecules present on the liposome surface. Captured liposomes can be observed as a visible red band on the test line and the control line.

$(0.0158 \% \mathrm{w} / \mathrm{w})$. The entire analysis takes about $2 \mathrm{~h}$ without the requirement of sophisticated equipment or skilled operators.

\section{Materials and methods}

Materials

Raw peanuts, chocolates, legumes, nuts, and non-fat dry milk were purchased from a local food market (Geneva, NY). In this study, bittersweet chocolate made by Swiss Chocolate Ltd. (St. Gallen, Switzerland) was used. Blocker casein and avidin were purchased from Pierce (Rockford, IL). Polyvinyldifluoride (PVDF) membranes were bought from Millipore (Bedford, MA). Anti-rabbit IgG (Fc fragment specific) alkaline phosphatase conjugates and BCIP/ NBT (bromochloroindolyl phosphate/nitro blue tetrazolium) substrates were purchased from Promega (Madison, WI). Nitrocellulose (NC) membranes (AE100), absorbent pad (type 900 wicking paper), and conjugate pads (12-S) were from Schleicher and Schuell (Dassel, Germany). Dipalmitoyl phosphatidylcholine (DPPC), dipalmitoyl phosphatidylethanolamine (DPPE), dipalmitoyl phosphatidylglycerol (DPPG), and 1,2-dipalmitoyl-sn-glycero3-phosphoethanolamine- $N$-(cap-biotinyl) (DPPE-biotin) were bought from Avanti Polar Lipids, Inc. (Alabaster, AL). Goat serum was obtained from Quad Five (Ryegate, MT). Ethyl acetate, chloroform, and hexane (HPLC grade) were bought from Fisher (Pittsburgh, PA). All other chemicals were purchased from Sigma (St. Louis, MO).

\section{Test strip preparation}

The test strips were prepared as described in the previous study [14]. Briefly, the test strip consisted of a laminated card on which the NC membrane, conjugate pad, and absorbent pad were attached, as shown in Fig. 1. On the NC membrane, $2 \mu \mathrm{g}$ of anti-Ara h1 antibody was coated as a test line per test strip, while $0.25 \mu \mathrm{g}$ of avidin was coated as the control line per test strip.

\section{Ara h1-tagged liposomes preparation}

Ara h1-tagged liposomes were prepared as previously described [14]. Briefly, ATA-liposomes were prepared from a mixture of DPPC, DPPG, cholesterol, DPPE-biotin and DPPE-ATA (molar ratio of 43:5:45:3:4), with $150 \mathrm{mM}$ SRB solution, by a hydration/ freeze-thaw/extrusion method. Ara h1-tagged liposomes were produced by conjugating maleimide derivatized Ara h1 to sulfhydryl-liposomes, produced from ATA-liposomes by deprotection with hydroxylamine. Ara h1-tagged liposomes were separated from unbound Ara h1 on a Sepharose CL-4B column with Tris-buffered saline $\left(0.02 \mathrm{M}\right.$ Tris with $0.15 \mathrm{M} \mathrm{NaCl}, 0.01 \% \mathrm{NaN}_{3}, \mathrm{pH} 7.5$, plus sucrose to make osmolality $535 \mathrm{mmol} / \mathrm{kg}$ ).

\section{Assay format}

The sample solution $(20 \mu \mathrm{l})$ was placed in a glass tube $(12 \mathrm{~mm} \times 75 \mathrm{~mm})$, and then a test strip was inserted into this tube. After the sample solution was absorbed, a mixture of $10 \mu \mathrm{l}$ Ara h1tagged liposomes and $10 \mu \mathrm{l}$ Blocker casein was added to the same glass tube and allowed to be absorbed, followed by the addition of $50 \mu$ l Blocker casein. Once solution was completely absorbed into the strip, the test strip was taken out, and the signal intensity of the test line was measured by conversion into gray scale readings by Scan Analysis densitometry software (Biosoft, Ferguson, MO). When the assay is performed properly, the control line is visible above the test line as confirmation.

\section{Sample homogenization}

Peanuts and chocolate were frozen with liquid nitrogen and ground in a food processor, followed by mortar and pestle, in order to get homogenized fine particles. After homogenization, ground samples were stored at $-20{ }^{\circ} \mathrm{C}$ until used.

\section{Optimization of the extraction buffer}

A two-phase extraction system, including an aqueous extraction buffer layer and an organic solvent layer, was used to extract Ara h1 from the peanut-spiked chocolate. An optimal extraction buffer was selected from 18 different buffers. The tested buffers were prepared as $20 \mathrm{mM} \mathrm{NaH} \mathrm{PO}_{4}$ containing $0.1 \mathrm{M}$ or $1.0 \mathrm{M} \mathrm{NaCl}$ either with or without $5 \%$ of fish skin gelatin or NFDM, and $\mathrm{pH}$ of $7.5,9.0$ or 11.5 . Each extraction buffer $(20 \mu \mathrm{l})$ was analyzed in the developed LFA. The best extraction buffer was selected on the basis of the highest signal intensity on the test line.

\section{Optimization of the organic solvent}

The optimal organic solvent was selected on the basis of the extraction efficiency of three organic solvents: ethyl acetate, chloroform, and hexane. The extraction efficiency was determined by total protein concentration of the extracted sample in the buffer layer and by the signal intensity on the test line in the LFA. Total protein concentration was determined by the Bio-Rad protein assay with BSA as the standard. Ground peanut and chocolate were weighed and combined to produce the spiked sample as $5 \mathrm{mg}$ peanuts in $0.5 \mathrm{~g}$ chocolate $(1 \% \mathrm{w} / \mathrm{w})$. Extraction of Ara h1 was performed in an $18 \mathrm{~mm} \times 150 \mathrm{~mm}$ glass tube with a mixture of $1 \mathrm{ml}$ of the extraction buffer (PBS: $20 \mathrm{mM} \mathrm{NaH}_{2} \mathrm{PO}_{4}, 0.1 \mathrm{M} \mathrm{NaCl}, \mathrm{pH}$ 7.5 ) and $4 \mathrm{ml}$ of organic solvent, at $35^{\circ} \mathrm{C}$ for $30 \mathrm{~min}$ with shaking at $200 \mathrm{rpm}$. The buffer portion $(0.5 \mathrm{ml})$ was separated from the organic solvent after centrifugation at $13,000 \mathrm{rpm}$ at $4{ }^{\circ} \mathrm{C}$ for $1 \mathrm{~min}$, and treated with $50 \%(\mathrm{w} / \mathrm{v})$ insoluble PVPP on rotary mixer at $35{ }^{\circ} \mathrm{C}$ for $30 \mathrm{~min}$. The supernatant was separated from PVPP after centrifugation at $13,000 \mathrm{rpm}$ at $4{ }^{\circ} \mathrm{C}$ for $15 \mathrm{~min}$, and $20 \mu \mathrm{L}$ of this solution was analyzed by the developed LFA.

Optimization of the extraction time and temperature

The best combination of extraction time and temperature was selected on the basis of the lowest signal intensity on the test line of 


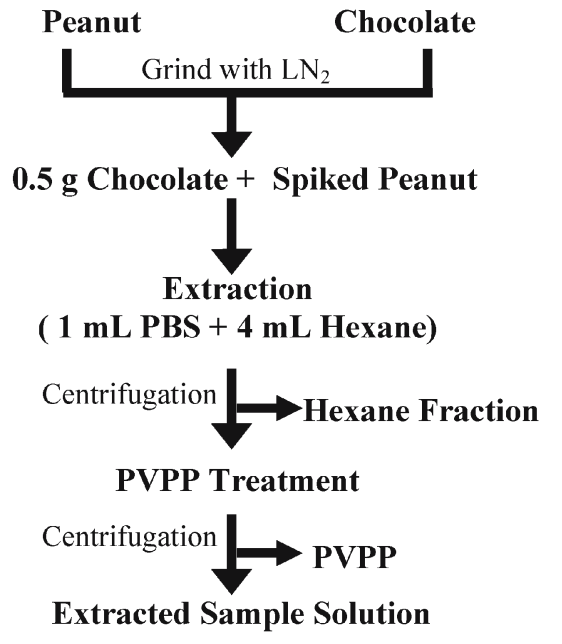

Fig. 2 Simplified scheme for the optimized extraction procedure of Ara h1 from peanut-spiked chocolate. Sample was extracted and defatted simultaneously with the two-phase mixture of PBS and hexane, followed by treatment with insoluble PVPP.

the LFA. Chocolate samples with $1 \%$ peanuts were extracted with $1 \mathrm{ml}$ of PBS and $4 \mathrm{ml}$ of hexane at $25,35,45$ and $55^{\circ} \mathrm{C}$ for 15,30 , 45 and 60 min with shaking at $200 \mathrm{rpm}$. The buffer portion was separated from hexane after centrifugation at $13,000 \mathrm{rpm}$ at $4{ }^{\circ} \mathrm{C}$ for $1 \mathrm{~min}$. After treatment with $50 \%(\mathrm{w} / \mathrm{v})$ of insoluble PVPP, the extracted sample solution was analyzed by the LFA.

Cross-reactivity study for anti-Ara h1 antibody

Protein extracts from legumes (peanut, red lentil, navy bean, red kidney bean and yellow split pea), and nuts (pistachio, cashew, almond and hazelnut) were analyzed by a Western blot with the anti-Ara h1 antibody. All samples were extracted with the optimized two-phase extraction system at $35{ }^{\circ} \mathrm{C}$ for $30 \mathrm{~min}$ with shaking at $200 \mathrm{rpm}$. After the PVPP treatment, the extracted proteins $(0.5 \mu \mathrm{g})$ were separated by SDS-PAGE and analyzed by a Western blot.

Determination of the limit of detection (LOD)

Different amounts of peanuts in chocolate were used to determine the LOD for the optimized sample preparation procedure with the LFA. Chocolate was spiked with various amounts of peanuts (39, $156,625,2500,10,000 \mathrm{ppm})$. Extraction of Ara h1 from peanutspiked chocolate was performed according to the scheme shown in Fig. 2. The extracted Ara h1 samples were analyzed by the LFA, and a dose-response curve was generated from the gray scale intensity of the signal on the test line. The LOD was calculated from the dose-response curve as the concentration equivalent to the mean of chocolate samples without peanuts (negative control) minus 3 standard deviations.

\section{SDS-PAGE and western blot}

SDS-PAGE was performed as described by Laemmli [16] with modification for a BioRad Mini Protean II system with precast 4$20 \%$ Tris-glycine gel. Gels were stained with Coomassie Brilliant Blue G-250. For the Western Blot, proteins from the gel were transferred into the PVDF membrane at $100 \mathrm{~mA}$ for $1 \mathrm{~h}$, as described by Towbin et al. [17]. Membranes were blocked with 5\% (w/v) NFDM in $10 \mathrm{mM}$ Tris ( $\mathrm{pH} 7.5), 150 \mathrm{mM} \mathrm{NaCl}, 0.05 \%$ Tween-20 (TBST) for $1 \mathrm{~h}$ at room temperature. Antibody solutions against Ara h1 were diluted to $100 \mathrm{ng} / \mathrm{ml}$ in TBST, and incubated with the membrane for $1 \mathrm{~h}$ at room temperature. After washing with TBST, bound antibodies were detected using anti-rabbit IgG conjugated to alkaline phosphatase. The membrane was washed again with TBST, and the captured anti-rabbit IgG complexes were visualized by the addition of BCIP/NBT as described by the supplier (Promega).

\section{Results and discussion}

\section{Optimization for the extraction of Ara h1}

Chocolate contains an excess of lipids and phenolic compounds $[13,18]$ that can reduce the extraction efficiency of Ara h1 and, therefore, the sensitivity of the LFA. To eliminate these two major interfering components, we studied a two-phase extraction system consisting of a mixture of an aqueous extraction buffer and an organic solvent. This novel extraction system was used to delipidate the chocolate sample and to extract Ara h1 simultaneously, resulting in a faster and simpler procedure for extraction.

The first task in this study was the selection of an optimal extraction buffer that had the smallest negative effect on the sensitivity of the developed LFA. That is, the best extraction buffer should give the highest signal on the test line. In previous studies, different kinds of extraction buffers had been used to increase the assay sensitivity for the detection of peanut contamination $[9,11$, $19,20]$. Several researchers reported that phenolic compounds in chocolate significantly reduced the sensitivity of assays [9, 11]. Because of that, fish skin gelatin or NFDM had been used in extraction buffers to block the interference of phenolic compounds. Moreover, to increase protein solubility in the extraction buffer, a broad range of concentrations $(0.2-1.0 \mathrm{M})$ of $\mathrm{NaCl}$ had been applied [19, 20]. Therefore, in this study we tested 18 different phosphate $\left(20 \mathrm{mM} \mathrm{NaH} \mathrm{NO}_{4}\right)$ buffers, which were supplemented with $5 \%$ gelatin or 5\% NFDM, with $0.1 \mathrm{M}$ or $1.0 \mathrm{M} \mathrm{NaCl}$, at $\mathrm{pH} 7.5,9.0$ or 11.5 . As shown in Fig. 3, the phosphate buffers with $1.0 \mathrm{M} \mathrm{NaCl}$ generally gave significantly lower signals compared to those with $0.1 \mathrm{M} \mathrm{NaCl}$. Most likely, this signal reduction was caused by the presence of large amounts of $\mathrm{NaCl}$, which interfered with electrostatic interactions between the Ara h1 molecules on the liposome surface and the antibodies immobilized on the test strips. Moreover, among the phosphate buffers with $0.1 \mathrm{M} \mathrm{NaCl}$, the signal intensity of buffers with fish skin gelatin or NFDM as additives was lower compared to those buffers without these additives. This signal decrease was likely a result of the non-specific blocking of the antigen-antibody interactions due to the excess of gelatin or NFDM. Fig. 3 shows that among the phosphate buffers with $0.1 \mathrm{M} \mathrm{NaCl}$, without any additives, the one at $\mathrm{pH} 7.5$ gave a much higher signal compared to buffers at $\mathrm{pH} 9.0$ or 11.5. Therefore, the phosphate buffer with $0.1 \mathrm{M} \mathrm{NaCl}$ at $\mathrm{pH} 7.5$ was chosen as the best extraction buffer for further optimization. 


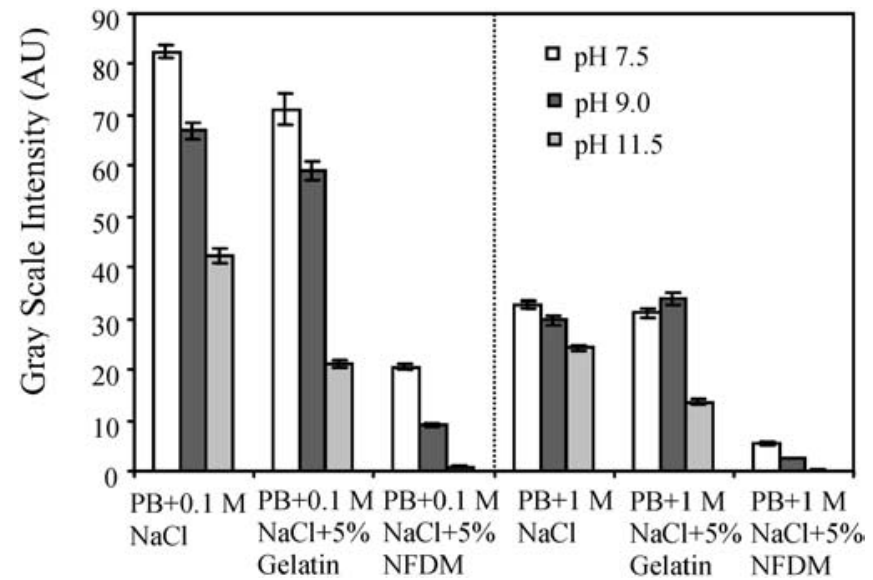

Fig. 3 Effect of the extraction buffer on the lateral flow assay with Ara h1-tagged liposomes. Extraction buffer was mixed with Ara h1-tagged liposomes, and then analyzed for its effect on the signal intensity of the test line. (PB: $20 \mathrm{mM}$ sodium phosphate buffer; NFDM: non-fat dry milk).

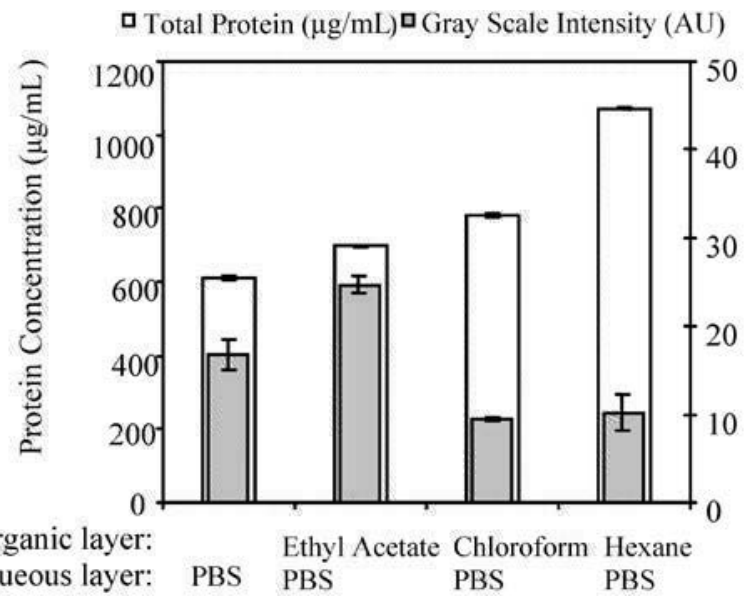

Fig. 4 Effect of organic solvents on protein extraction efficiency and the sensitivity of the competitive lateral flow assay. Protein concentration of extraction products were determined by Bio-Rad protein assay. The signal intensity of the test line was measured and converted into gray scale intensity by a computer scanning program.

Chocolate contains about 30\% lipids by weight [13], and this large amount of lipids can reduce the extraction efficiency of protein by lowering their solubility in the extraction buffer. Because the objective of this study was to improve the Ara h1 extraction efficiency, eliminating lipids from the protein sample was the second task for optimization. Three frequently used organic solvents for delipidation were chosen in this study: ethyl acetate, chloroform, and hexane [21-23]. Chloroform is particularly efficient for lipids of intermediate polarity, while hexane is a good solvent for lipids of low polarity. After Ara h1 extraction, each aqueous portion of the sample was analyzed by the Bio-Rad protein assay to determine the total protein concentration, and by the LFA to detect the extracted Ara h1. Fig. 4 shows the effect of organic
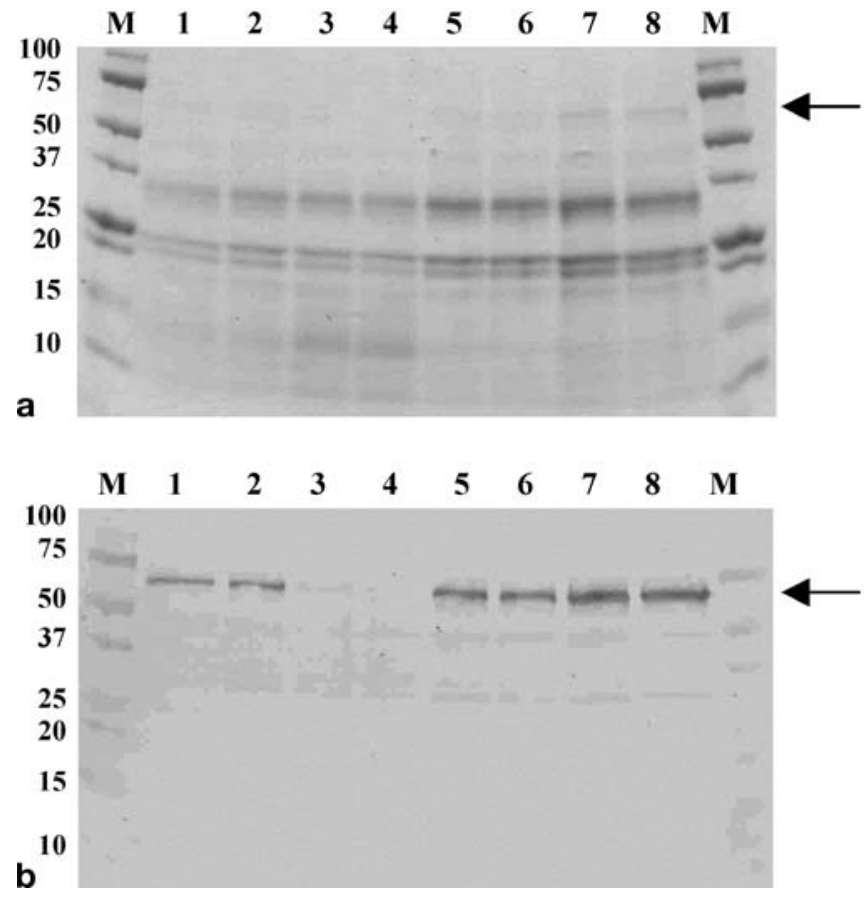

Fig. 5 Comparison of the extraction efficiency of Ara h1 with and without different organic solvents by (a) SDS-PAGE and (b) Western blot. Line M is the protein standards (kDa). Samples extracted with only PBS buffer are in lines 1-2, with ethyl acetate in lines 3-4, with chloroform in lines 5-6, and with hexane in lines $7-$ 8. The arrows indicate the expected position of Ara h1.

solvents on protein extraction efficiency and the signal intensity of the competitive LFA. The protein concentration of the extraction product was related to the polarity of the organic solvent. The extraction system containing the organic solvent with highest polarity extracted less protein from chocolate sample compared to the system containing the organic solvent with lowest polarity. The order of protein concentration from different extraction systems was buffer $<$ ethyl acetate $<$ chloroform $<$ hexane. This order is the opposite of the polarity index of these organic solvents, which is water (high polarity) $>$ ethyl acetate $(0.58)>$ chloroform $(0.4)>$ hexane $(0.01)$. The solvent with lowest polarity can extract more lipids from chocolate, resulting in a lower content of lipids in the aqueous buffer layer, so a higher concentration of proteins can be extracted. The signal intensity of the extraction system with ethyl acetate is higher than that of extraction buffer, even through it has higher protein concentration. This higher signal intensity may be due to a lower amount of Ara h1 in the product. To understand the cause of this signal increase, all the extracted samples were analyzed by SDS-PAGE and Western blot with anti-Ara h1 antibodies. The data show that the total amount of protein per line on the SDS-PAGE (Fig. 5a) is directly proportional to the protein concentration as determined by the Bio-Rad protein assay (Fig. 4). Moreover, the Western blot (Fig. 5b) indicated that the extracted sample with ethyl acetate contained a very low amount of Ara h1 compared with other extraction systems. This explained why the 


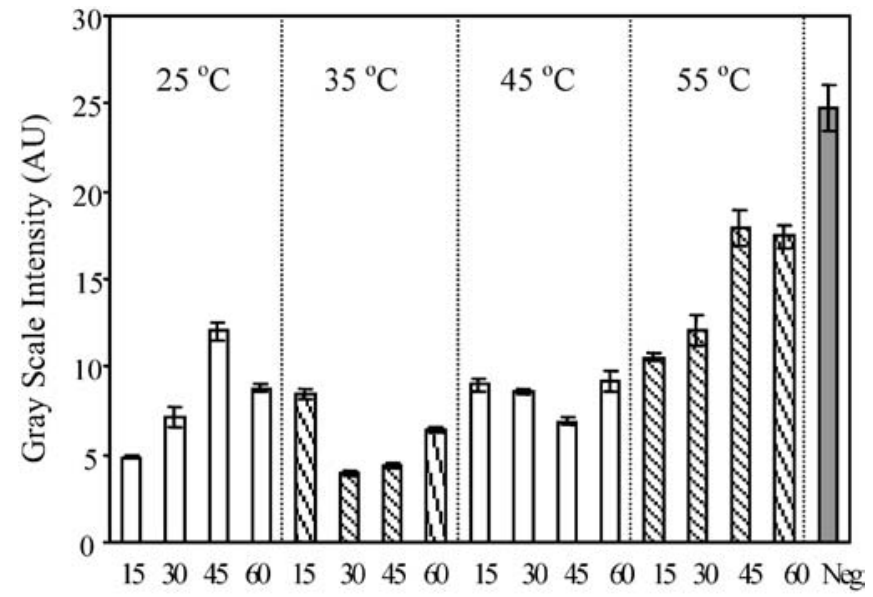

Extraction Time (min)

Fig. 6 Effects of temperature and time on the signal intensity in the competitive lateral flow assay for peanut-spiked chocolate samples. Samples were extracted at $25,35,45$ and $55{ }^{\circ} \mathrm{C}$ for $15,30,45$ and 60 min using the PBS and hexane mixture.

extraction system with ethyl acetate had the highest signal in the competitive LFA (i.e., the lowest Ara h1 concentration). Furthermore, the Western blot also shows that the extraction system with hexane gave the highest signal for Ara h1 and was consistent with the data presented in Fig. 4. For further optimization, hexane was chosen as the organic solvent for the extraction system.

It is well known that the extraction temperature has a significant effect on the extraction efficiency [24]. Increasing the extraction temperature can enhance the extraction efficiency. However, if the temperature is too high or the extraction time is too long, proteins may be denaturated, especially under harsh conditions, such as in the presence of hexane. To find the best temperature and time for extraction, we investigated 16 combinations of temperature $\left(25,35,45\right.$ and $\left.55^{\circ} \mathrm{C}\right)$ and time $(15,30,45$ and $60 \mathrm{~min}$ ). The extraction efficiency was evaluated by the signal intensity in the competitive LFA. The lower the signal means the higher extraction efficiency of Ara h1. The sample extracted at $35^{\circ} \mathrm{C}$ for 30 min gave the lowest signal on the test line as shown in Fig. 6, so this combination of extraction time and temperature was selected as the best conditions for the extraction of Ara h1 from chocolate.

\section{Cross-reactivity of anti-Ara h1 antibody}

Peanut plants (Arachis hypogea) belong to the botanical family of Leguminosae, while in the non-botanical classification, peanut is a member of the nut family. To evaluate the cross-reactivity of the anti-Ara h1 antibody used in the LFA to other legumes and nuts, we extracted proteins from five legumes (peanut, red lentil, navy beans, red kidney beans, and yellow split peas) and four nuts (pistachio, cashew, almond, and hazelnut). Proteins were

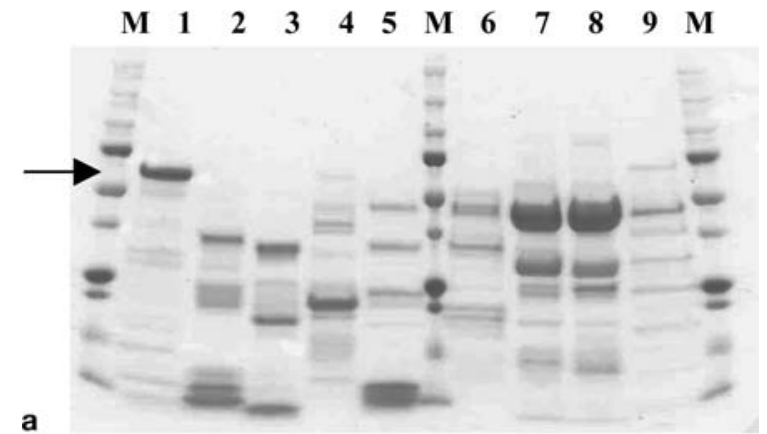

$\begin{array}{llllllllllll}M & 1 & 2 & 3 & 4 & 5 & M & 6 & 7 & 8 & 9 & M\end{array}$

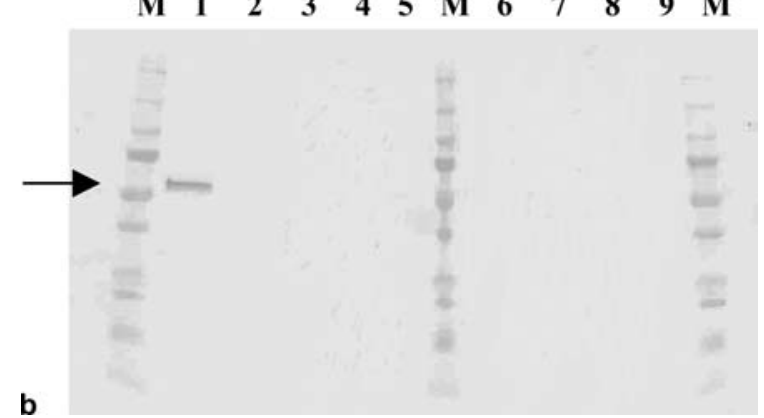

Fig. 7 Cross-reactivity of the anti-Ara h1 antibody with proteins extracted from various nuts and legumes. (a) SDS-PAGE and (b) Western Blot of nuts and legumes: line 1, peanut; 2, pistachio; 3, cashew; 4, almond; 5, hazelnut; 6, red lentil; 7, navy bean; 8, red kidney bean; and 9, yellow spit pea. Line $M$ contained prestained protein standards with molecular weights of $250,150,100,75,50$, $37,25,20,15$, and $10 \mathrm{kDa}$. The arrows indicate the expected position of Ara h1.

separated on SDS-PAGE (Fig. 7a) and then analyzed by Western blot using anti-Ara $\mathrm{h} 1$ as the primary antibody (Fig. 7b). We selected pistachio, cashew, almond, and hazelnut because they are common ingredients in chocolate. The anti-Ara h1 antibody showed no cross-reactivity to either other peanut proteins or proteins from the tested legumes or nuts. Only one protein $(\sim 65 \mathrm{kDa})$ extracted from peanuts showed immunoreaction with the anti-Ara h1 antibodies. On the basis of the previous study [14], this protein is Ara h1, and this result demonstrates the high specificity of anti-Ara h1 antibody to Ara h1.

\section{Assay sensitivity}

To determine the limit of detection (LOD), different amounts of peanuts were spiked in chocolate and the extracted Ara h1 was detected by the LFA to generate a dose-response curve, as shown in Fig. 8. The LFA is on the basis of the competition between Ara h1 in the sample and Ara h1 on the liposome surface for binding to the immobilized anti-Ara $\mathrm{h} 1$ antibodies on the test line of the test strips (Fig. 1). Therefore, the more Ara h1 molecules in the sample, the less signal intensity is produced on the test line. 


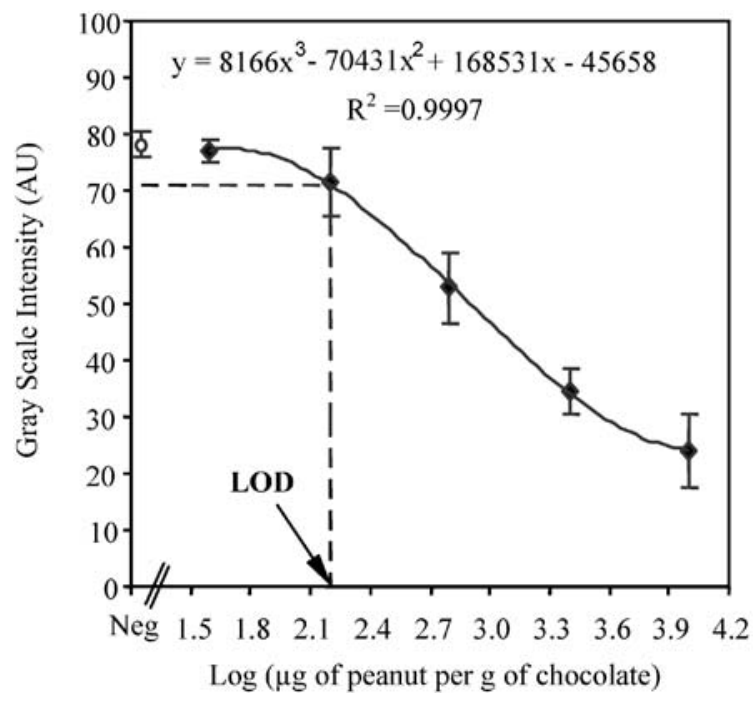

Fig. 8 Dose-response curve for different amounts of spiked peanuts in chocolate $(0,39,156,625,2500,10,000 \mu \mathrm{g}$ of peanut/g of chocolate). Ara h1 was extracted from peanut-spiked chocolate and analyzed in a competitive lateral flow assay. The dose-response curve was generated by gray scale intensity of the signal on the test strips. The curve is a three-parameter sigmoidal function $\left(R^{2}=0.9997\right)$, and the limit of detection (LOD) was calculated as $158 \mu \mathrm{g}$ peanut/g of chocolate.

Figure 8 shows a three-parameter sigmoidal function having a significantly high $R^{2}$ value of 0.9997 . From this function, the LOD was calculated to be $158 \mu \mathrm{g}$ of peanut $/ \mathrm{g}$ of chocolate with the dynamic range between ca. 158 and $2000 \mu \mathrm{g}$ of peanut/g of chocolate. Furthermore, this study is the first one to use a two-phase extraction system for separation of Ara h1 from chocolate. Additionally, we successfully used PVPP to eliminate phenolic compounds from chocolate to improve the signal in the LFA. The entire analysis time (from sample preparation to detection) was around $2 \mathrm{~h}$. Compared to the ELISA assay published by Pomes et al. [11], in which the LOD is 160-330 $\mu \mathrm{g}$ peanut/g chocolate $(0.016-0.033 \%)$, this liposome-based lateral flow assay has somewhat higher sensitivity but is easier and less costly to perform than an ELISA.
Acknowledgement W.-H. Wen acknowledges with appreciation the award of the Vitasoy \& Lo Fellowship

\section{References}

1. Al-Muhsen S, Clarke AE, Kagan RS (2003) CMAJ 168:1279_ 1285

2. Grundy J, Matthews S, Bateman B, Dean T, Arshad SH (2002) J Allergy Clin Immunol 110:784-789

3. Sampson HA (1996) BMJ 312:1050-1051

4. Pumphrey RS, Stanworth SJ (1996) Clin Exp Allergy 26:13641370

5. Yocum MW, Khan DA (1994) Mayo Clin Proc 69:16-23

6. Kemp SF, Lockey RF (1996) JAMA 275:1636-1637

7. Bock SA, Atkins FM (1989) J Allergy Clin Immunol 83:900904

8. Keck-Gassenmeier B, Benet S, Rosa C, Hischenhuber C (1999) Food Agric Immunol 11:243-250

9. Stephan O, Vieths S (2004) J Agric Food Chem 52:3754-3760

10. Stephan O, Möller N, Lehmann S, Holzhauser T, Vieths S (2002) Eur Food Res Technol 215:431-436

11. Pomes A, Vinton R, Chapman MD (2004) J Food Prot 67:793798

12. Xu L, Diosady LL (2002) Food Res Int 35:23-30

13. Anon. (1999) Nutrition Information of Dark Chocolate-USDA Nutrient Database for Standard Reference, Release 13. USDA, Washington, D.C.

14. Wen HW, Borejsza-Wysocki W, DeCory RT, Durst RA (2005) Anal Bioanal Chem (submitted)

15. Ahn-Yoon S, DeCory TR, Durst RA (2004) Anal Bioanal Chem 378:68-75

16. Laemmli UK (1970) Nature 227:680-685

17. Towbin H, Staehelin T, Gordon J (1979) Proc Natl Acad Sci USA 76:4350-4354

18. Hannum SM, Erdman JW Jr (2000) J Med Food 3:77-105

19. Pomes A, Helm RM, Bannon GA, Burks AW, Tsay A, Chapman MD (2003) J Allergy Clin Immunol 111:640-645

20. Mills ENC, Potts A, Plumb GW, Lambert N, Morgan MRA (1997) Food Agric Immunol 9:37-50

21. Folch J, Lees M, Sloane Stanley GH (1957) J Biol Chem 226:497-509

22. Lusas EW, Riaz MN (1995) J Nutr 125:573S-580S

23. Lin JH, Liu LY, Yang MH, Lee MH (2004) J Agric Food Chem 52:4984-4986

24. Harris ELV, Angal S (1989) Protein purification methods. IRL Press, Oxford, New York 